\title{
Teachers training for arranging a developing subject-space environment in a preschool organization
}

\author{
I.V. Zotova ${ }^{1 *}$ \\ ${ }^{1}$ State Budget Educational Institution of Higher Education of the Republic of Crimea Crimean \\ Engineering and Pedagogical University the name of Fevzi Yakubov, Simferopol, Russia
}

\begin{abstract}
The analysis of the subject-space developmental environment of the preschool educational organization included several components. Among them, we outline the assessment of the quality of the subject-space developmental environment created in each age group of the kindergarten for the general development of children. The next component is taking into account kindergarteners' self-assessment of the correspondence of the subject-space developmental environment of the kindergarten groups to the principles of its organization. The results of the assessment of the quality of the subject-spatial developmental environment, created in each age group of the kindergarten for general development, carried out by teachers, are presented. The results of studying the potential of a preschool institution are described. It is noted that teachers highly appreciate the capabilities of the preschool institution in terms of safety, accessibility of the location of objects and manuals for children. Teachers highly appreciate the subject space in terms of stimulating various types of children's activities, as well as the availability of zones and equipment, play material for play, cognitive, artistic and aesthetic activities.
\end{abstract}

\section{A problem statement}

The conditions of modernization of the Russian educational system, as well as variability of educational programs and reformation of the preschool education system define the growing urgency of the problem of organizing such an environment that would be "aimed at harmonization in terms of quantity, diversity, originality, changeability, and the degree of influence on the child" of all its components that contribute to the all-round development of the child's personality.

In the context of the foregoing, the main thing under consideration is the influence of the subject-space environment on the development of preschool children in accordance with their age characteristics, the protection and strengthening of their health and the improvement of their emotional well-being.

\footnotetext{
* Corresponding author: prof-ped.gpa@mail.ru
} 
Hence, there is a need for a competent organization of the development of subject-space environment, which will ensure the active involvement of the child in interaction with the surrounding subject world, thereby becoming one of the conditions for the implementation of the main educational program of preschool education. At the same time, the developing effect of the subject-space environment of the kindergarten largely depends on the ability of teachers to reveal the social potential of the objective world, to use it as an educational tool.

In the requirements for exemplary educational programs, the subject-space environment is designated as one of the key conditions for a successful educational process. With that, the design and enrichment of the developing subject-space environment is the key task of preschool organizations. The subject-space environment should stimulate children to be active in various types of activities, to develop abilities.

\subsection{The objective of the work}

In order to determine the theoretical significance of the research problem, review the literature used and define the key concept of the research, theoretical methods such as analysis, synthesis and modeling were used. Pedagogical experiment was chosen as the leading research method with the aim of revealing the training of future teachers in design and arrangement of the developing subject-space environment in a preschool organization. It is known that the environment in which a child lives and is brought up may be different: supportive, developing, rich, comfortable, or in some cases even hostile (E.I. Ivanova [1], V.S. Sobkin [2], N. Polinsky [3], C.C. Loyola [4], E.B. Plaksina [5], A.V. Shin [6] and others).

The analysis of sources shows that various approaches to organizing the subject-space environment have been considered to one degree or another by many researchers (E.V. Baryshnikova [7], V.A. Yasvin [8], Berk Özler [9], N.Yu. Belikova [10], M. Angeles [11], N.V. Bordovskaya [12], Z.U. Kolokolnikova [13]), however, at the present stage it needs a more detailed, systematic pedagogical study, especially in the context of the developing effect of the environment.

\section{Results of the research}

The system of higher education in modern Russia is aimed at the professional training of highly qualified, competent teaching staff. Its contents should be based on modern teaching technologies that graduates master in the learning process. For this, it is necessary to replace the reproductive-functional model of education with a professional-competence one. The analysis of scientific works indicates that the communicative competence that we are examining is considered in the context of professional competence. It is needed to perform professional tasks in the context of multifunctional relationships and interactions. In these conditions, the need for specialists with a high level of development of social and communicative competence, including future teachers, is extremely relevant.

In the field of preschool pedagogy, the term "developing environment" is understood as "a complex of material and technical, sanitary and hygienic, aesthetic, psychological and pedagogical conditions that ensure the organization of the life of children and adults", it is important to take into account many factors in its formation.

Taking into account the age characteristics of each of the groups of the preschool educational organization is fundamental here. When creating a subject-developing environment for any age group in a preschool educational organization, it is necessary to take into account the psychological foundations of constructive interaction between the participants of the educational process, as well as the design and ergonomics of the modern 
environment of the preschool educational organization along with psychological characteristics of the age group targeted by this environment.

A developing subject-space environment of a preschool educational organization is understood as a rationally organized and aesthetically designed environment filled with a variety of objects and play materials, which is comfortable and safe for children and contributes to their personal development.

It ensures the simultaneous inclusion of the entire group in various activities, taking into account their age-related psychological characteristics, needs and interests. A competently created and organized subject-space developmental environment brings up in children confidence in their strengths and capabilities, independence, initiative, purposefulness, creativity. For this environment to be effective, it must, first of all, be filled with play equipment that meets the age-specific needs of definite children.

Yu.Yu. Zolotukhina believes that the developing environment in a preschool organization should first of all provide a variety of activities for each child. This is achieved by the unity of the natural and social components of the environment. This scientist has developed options for design projects of a subject-space developmental environment for preschool organizations, "which include architectural and landscape and natural-ecological objects, art studios, sports and playgrounds, thematic sets of toys, manuals" [14].

According to M.N. Polyakova, the subject-space developmental environment is "a form of communicative interaction that creates special types of community between the child and the teacher, which ensure the transfer of socio-cultural experience, norms and rules of moral behavior to children, which they need to function successfully in the society" [15].

The subject-space environment of the kindergarten, what the child is directly in, largely determines his emotional state, forms a situation of positive communication with the outside world. Objects, furniture, equipment, all that "interior decoration" that surrounds the child during the whole day of his stay in kindergarten should be holistic and harmoniously combined in color, style, materials.

In addition, the environment should develop a sense of beauty in the pupils and bring psychological comfort. But it can be very difficult to create such an environment in a preschool organization as teachers often lack professional knowledge and skills.

Taking into account the changes in certification of pedagogical workers of a preschool educational institution, it was decided that the expert opinion on the level of professional activity of a future teacher will be based on the results of pupils' acquisition of educational programs and indicators of the dynamics of their educational achievements.

Here, an important task of a teacher in preschool educational organizations remains to improve the pedagogical process and increase the developmental effect of educational work with children through the organization of a developing subject-space environment, taking into account the age characteristics of children.

Thus, it is expedient to summarize the research on the problems of training future teachers for design and organization of a developing subject-space environment that provides an individual vector of a child's development as an indicator of the professional competence of future teachers of an educational institution.

The main tasks of the researches were defined as follows:

- to create a design project of a subject-space environment that ensures respect for the personality of each child, develops his self-confidence, initiative, creativity, independence and responsibility, the ability to accept and implement changes, think critically, make choices, set and solve problems, show creativity, imagination, ingenuity, take care of people, society, country, the world around;

- for teachers - to master new educational technologies that form in children a desire to gain the knowledge of new things, to learn throughout their lives; 
- for teachers - to obtain new educational technologies and methods of working with children that would contribute to the increase of their professional competence within the framework of the subject-space environment;

- to reach a high level of aesthetics and modernization of the space of a childcare institution, taking into account the requirements of modern design and competencies of teachers of a preschool educational organization.

The forms of training future teachers were chosen based on the psychological and pedagogical characteristics, their cognitive activity. So, methodical work provides for the following innovative forms: lectures in the form of a dialogue, workshops, master classes, competitions, a workshop on creating sketches and mini-projects, game modeling, project method and problem-search.

The aim is to develop and individualize the subject-space environment and create a system of methodological work directed at the formation of competence of future teachers in the social and emotional development of children, which allows interacting with the child on principles of a personality-oriented model.

The experimental work is carried out in three stages according to the developed plan.

At the first, preparatory, stage, during a variety of pedagogical activities, future teachers study specialized literature, Internet sites on the organization of an individualized environment, and then, taking into account the acquired knowledge, teachers discussed and proposed an individualized design of the institution's space.

At the second, main, stage, individual projects for each group, a plan for the functioning of the subject-space environment of a preschool educational organization were developed and introduced into the annual plan. In parallel, there an exchange of experience was conducted: in the methodological office, libraries for educators were formed, didactic materials were prepared and systematized.

At the last stage, the results were summed up, future work was planned for the following year.

A modern kindergarten is a place where a child gains experience of wide emotional and practical interaction with adults and peers in the most significant spheres of life for his development. Based on the studies carried out and the problems identified, it became obvious that the premises of the preschool institution, the projects of which were developed in the 1970s - 1980s, in some cases do not meet modern requirements for organizing the life of children in kindergarten. An important aspect in the development of the project is the creation of a design that meets the modern requirements of the organization of space, the implementation of the educational tasks of the kindergarten, directed at the artistic and aesthetic development of pupils and promoting the popularization of the institution in the district and the city.

In the federal educational standard, one of the conditions for the implementation of the basic educational program of preschool education is the requirements for the development of a subject-space environment.

In the professional standard of a teacher, one of the competencies of a preschool teacher, reflecting the specifics of work at the preschool level of education, is to participate in creating a psychologically comfortable and safe educational environment, ensuring the safety of children's life, preserving and strengthening their health, supporting the emotional well-being of the child during his stay in educational organizations.

Thus, the normative legal documents used in preschool education directly require the participation of the teaching staff in the creation and renewal of the subject world of the kindergarten, in which the socialization of preschoolers takes place.

Pedagogical design of the subject-space component of the educational environment from the point of view of Şenay Bulut Pedük [16], Deborah Moore-Russo [17], Terry Byers 
[18], I.S. Sklyarenko [19] and others relies on a system of requirements for its effective organization:

1) heterogeneity and complexity of the environment;

2) connectivity of functional areas;

3) flexibility and controllability of the environment;

4) ensuring the symbolic function of the environment;

$5)$ individualization of the environment (dissimilarity and uniqueness);

6) the authenticity of the environment (conformity to life manifestations).

A subject-development environment should serve the interests and needs of the child, enrich the development of specific types of activity, provide the zone of proximal development of the child, encourage them to make conscious choices, put forward and implement their own initiatives, make independent decisions, develop creative abilities, and also form the personal qualities of preschoolers and their life experience.

In the experimental work, a survey of teachers and parents of pupils was carried out. The results of the questionnaire survey of teachers showed that educators are not wellversed in the normative legal documents regulating the requirements for the content of a subject-space developmental environment of a preschool organization, they do not know the principles of organizing the environment well. The results of the questionnaire survey of parents showed that, in general, parents are satisfied with the organization of the subjectspace developmental environment of the preschool educational organization.

At the second stage of our experimental research, we were faced with the goal of testing the effectiveness of the implementation of pedagogical activities in organizing and designing a developing environment in a preschool educational organization. One of the forms of designing a developing subject-space environment is a design project. The term "design" is defined as a creative method and process of functional shaping, as well as the area of professional activity in the design of industrial products, furniture, tools, machines, the organization of the subject environment and work processes, a type of interdisciplinary design art and technical activity for the formation of the subject environment. Design activity consists in a specifically aesthetic way of forming objects, based on holistic comprehension.

Modern conditions require an innovative approach in creating the subject-space environment of the premises of groups, which act as a space for the life of children, providing maximum opportunities for the development of children's creativity, experimentation and research interest of each child. For this, it is necessary to draw up a holistic design project for a preschool educational organization.

Children and teachers are in kindergarten for a long time, so the main goal of the design project being created should be to create a space suitable for the life of pupils and the work of teachers. This means that the interior design should be the beginning of the creative process of the educator and the children's collective, actively supported by the parents of the pupils.

When developing the design of premises, the main goal of the concept for their design should be:

- integrity and consistency: all design should be connected into a single whole, there should not be random unrelated pieces of design;

- taking into account the individual interests of teachers: the design should be a logical continuation of the methodological work with children, therefore, all stages of work should be coordinated with educators working in these age groups;

- brevity and functionality: everything should be accessible to children so that everything can be touched, studied, played;

- the design project should be a joint action of the pedagogical, children's and parental teams. 
The developing subject environment is considered by us as a system of material objects of the child's activity, which functionally simulates the content of the development of his spiritual and physical appearance (V.N. Belkina [20], L.N. Latipova [21]).

Design project objectives:

1. To decorate the interior of group rooms, common areas (educational center, music hall, exhibition areas of the entrance groups of a preschool institution) allowing to implement the tasks of general and artistic and aesthetic development of pupils.

2. To develop and equip kindergarten premises with new universal equipment (modular constructs) intended for joint and independent activities of participants in educational relations, creating an opportunity for organizing play, artistic, creative, communicative and cognitive research activities of pupils.

3. To help children more fully (more comfortably) and more harmoniously feel their stay in the institution, learn to relate themselves to the surrounding reality by using the possibilities of color solutions of the environment as a means of emotional, aesthetic and psychological impact.

4. To increase the professional competence of teachers in the field of organizing and designing a developing environment for a preschool educational organization.

The main goal is to create and implement a design project of a developing subject-space environment of a preschool educational organization in the form of a constructed plan, in which the developing environment is presented as an integral system of interconnected objects that ensure the integrity of the pedagogical process and create an environment that meets the needs of the actual, immediate and future development of each child.

The design project will contribute to the arrangement of a creative atmosphere in the work of teachers, ensure a comfortable stay for children, parents, employees in the kindergarten.

The design project was developed on the basis of the following subprojects:

I. Library complex combined with a media library and a design studio;

II. Musical, theater and dance complex;

III. Exhibition centers, entrance groups to kindergarten;

IV. Centers for artistic and aesthetic development in group rooms.

The development of the project included the following stages:

1. Collection of information and survey of the environment.

2. Analysis of the results and prediction of new environmental effects.

3. Creation of an image of the subject-spatial environment.

4. Planning of actions for the development and implementation of a design project.

The basic interconnected components of the design project created on the basis of a preschool educational organization were centers for the artistic and aesthetic development of group rooms, a library complex, exhibition centers, entrance groups to a kindergarten, enriched with modular constructs developed on the basis of the institution, which we positioned as innovative universal equipment.

The concept, according to which each group has its own name and the corresponding design style, forms the basis of design developments for the design of dressing rooms for group rooms. For example, it contains business cards with photographs of children and teachers. Each preschooler has his favorite name written on his personal locker. In order to individualize the pedagogical process, the following components of the children's subculture are used. Each group has a stand or corner with pictures of children and their birthday. It can be supplemented with a horoscope, the name of the season, month, date. In the locker rooms of some groups, children's wishes for a birthday, New Year are placed, written down from their words by the teacher or the child himself (3-7 years old). In the group, the "Birthday Corner" is designed, the atmosphere of which is created with the help of colorful filling, "The Engine of Desires", a wonderful bag for gifts, etc. 
The headings "I can, I love, I want to learn" are filled in from the words of the child and reveal his interests and opportunities. You can track the emotional state of each child during the day thanks to the heading "My mood". Chips or magnets are placed in specially organized corners in accordance with the mood of preschoolers. Children learn to determine not only their own mood, but also the mood of their comrades.

An organized exhibition of the creativity of the parents and relatives of the child develops him and arouses a sense of pride in his family. A personality-oriented environment organized in this way in the premises and on the territory of a preschool institution stimulates communication, curiosity, and promotes the development of such vital social skills as initiative, independence, creativity in children.

The environment of the group, organized taking into account the individualization of the space of the child's life, is characterized by dynamism. Children feel competent and responsible and try to make the most of their capabilities and skills.

Experimental work made it possible to identify positive dynamics in the work carried out and contributed to the training of future literacy teachers in terms of organizing a developing subject-space environment. The goals and objectives for enriching the environment for the next period were outlined, observing the relationship between the analysis of the results of organizing the developing environment over the past year and planning work for the new academic year. A work plan was drawn up to enrich the developing environment and the possibility of timely making adjustments, which will enable the administrative staff to concretize and visually present the planned activities in all blocks.

It should be noted that the resources of social partnership were involved in the development and implementation of the design project.

After the diagnosis, a comparative description of the results obtained at the beginning and at the end of the study was compiled.

We have presented a comparative analysis of expert assessments of the subject-space environment of the kindergarten at the final stage of the experimental search work (Figure $1)$.



Fig. 1. Comparative analysis of expert assessments of the subject-space environment of the kindergarten at the final stage of the experimental search work. 


\section{Conclusions}

The design and implementation of the design project made it possible to organize a multifunctional environment in the groups, educational center and music hall. Modular constructs and their details are flexibly used to organize musical, performing, creative and play activities.

The creation of temporarily functioning zones and spaces of the library, design studio, music hall within the framework of the design project allows the pupils to simultaneously engage in various activities without interfering with each other, which indicates an increase in such a parameter as the "transformability of the environment".

The developing environment of the preschool institution has become more informatively rich (saturated), three groups and a music hall are equipped with multifunctional screens. Teachers replenish them with new equipment (games, costumes and attributes for performances), while expanding the forms of interaction with pupils.

Within the framework of the created design project, the pupils are provided with the opportunity to freely orient themselves in a familiar environment, on the one hand, and on the other, the opportunity is laid to introduce new ones, in accordance with the calendarthematic planning, educational tasks, the time of the year, and the age characteristics of children.

Analyzing the parameters of the environment for its variability, comparing the results of the initial and final stages of the questionnaire, we can make an unambiguous conclusion that the scores for this parameter have more than doubled. In general, summing up the empirical part of the study, we can conclude that the design of the subject-space environment made it possible to provide a developing effect in the field of artistic and aesthetic development of preschool children, through the phased development and implementation of a design project with the participation of the pedagogical staff of the preschool institution.

The work carried out contributed to an increase in the literacy of teachers in terms of organizing a developing environment. The goals and objectives for enriching the environment for the next period were outlined, observing the relationship between the analysis of the results of the organization of the developing environment over the past year and the planning of work for the new academic year. A work plan was drawn up to enrich the developing environment and the possibility of timely making adjustments, which will enable the administrative staff to concretize and visually present the planned activities in all the blocks.

\section{References}

1. E.V. Ivanova, I.A. Vinogradova, S.A. Zadadaev, Research of the school educational environment in the context of ensuring equal accessibility to education of a high quality, Education and science, 21(7), 69-89 (2019)

2. V.S. Sobkin, E.O. Smirnova, S. Ursula, A kindergarten bringing up a personality (a description of the "Amares» kindergarten, Köln, Germany)", Modern preschool education. Theory and practice, 8(90), 2018, 4-14 (2018)

3. N. Polinsky, R.F. Ellen, A.W. Devid, H. Uttal, The role of spatial abilities in young children's spatially-focused touchscreen game play, Cognitive Development, 57 (2021) 
4. C.C. Loyola, C.A. Grimberg, U.B. Colomer, Early childhood teachers making multiliterate learning environments: The emergence of a spatial design thinking process, Thinking Skills and Creativity, 36 (2020)

5. E.B. Plaksina, Speech development of a preschool-age child in a multicultural environment: the analysis of a teacher's educational activity, Pedagogical education in Russia, 6, 2019, 19-23 (2019)

6. A.V. Shin, I.V. Grosheva, Modeling a subject-space developmental environment in a preschool educational organization in the context of the State Curriculum of the Republic of Uzbekistan, Modern preschool education. Theory and Practice, 2(98), 6069 (2020)

7. E.V. Baryshnikova, Psychological safety of preschool children in the educational environment, Scientific notes of the University named after P.F. Lesgaft, 9(187), 442$445(2020)$

8. V.A. Yasvin, Formation of the theory of personality development environment in domestic educational psychology, Psychology. HSE Journal, 2, 295-314 (2020)

9. B.O. Lia, C.H. Fernald, P. Kariger, Ch. McConnell, M. Neuman, E. Fraga, Combining pre-school teacher training with parenting education: A cluster-randomized controlled trial, Journal of Development Economics, 133, 448-467 (2018)

10. N.Yu. Belikova, E.U. Ponomareva, V.V. Kotlyarova, S.V. Yushina, L.I. Abbasova, A.T. Latysheva, Professional and social self-determination of youth under conditions of the modernization of higher education, Revista Genero e Direito, 9(4), 846-859 (2020)

11. M.A. Ull, M.P. Martinez-Agut, A. Pinero, P. Aznar-Minguet, Perceptions and Attitudes of Students of Teacher-training towards Environment and Sustainability, Procedia-Social and Behavioral Sciences, 131, 453-457 (2014)

12. N.V. Bordovskaya, Challenges of the time and new models of the developing educational environment, Man and education, 2(35), 4-11 (2013)

13. Z.U. Kolokolnikova, Designing a subject-developing environment in primary school: the historical and pedagogical aspect", Problems of modern pedagogical education, 60-4, 218-221 (2018)

14. Y.Y. Zolotukhina, An environmental approach to the upbringing of preschoolers, Society: sociology, psychology, pedagogy, 4, 131-134 (2016)

15. M.N. Polyakova, Subject environment for the development of a child of preschool age, From PIDO kindergartens to the present day, Modern preschool education. Theory and Practice, 1(91), 46-57 (2019)

16. S.B Peduk, Investigation of Preschool Teachers' Opinions about Physical, Spatial Characteristics of Preschool Classrooms in Preschool Education Institutions, Procedi -Social and Behavioral Sciences, 143, 750-757 (2014)

17. D. Moore-Russo, J.M. Viglietti, M.M. Chiu, S.M. Bateman, Teachers' spatial literacy as visualization, reasoning, and communication, Teaching and Teacher Education, 29, 97-109 (2013)

18. T. Byers, W. Imms, E. Hartnell-Young, Evaluating teacher and student spatial transition from a traditional classroom to an innovative learning environment, Studies in Educational Evaluation, 58, 156-166 (2018)

19. I.S. Sklyarenko, N.V. Kodyakova, Organization of group learning activities as designing a personally developing educational environment, Bulletin of the Moscow University of the Ministry of Internal Affairs of Russia, 1, 249-255 (2019) 
20. V.N. Belkina, E.V. Shakirova, Design as a means of creating a developing subjectspatial environment for a kindergarten", Yaroslavl Pedagogical Bulletin, 3, 3337 (2019)

21. L.N. Latipova, Design-projection of the subject-developing environment of preschool education, Russian Journal of Education and Psychology, 8, 151-160 (2017) 